\title{
Bảo đảm an ninh kinh tế trong giai đoạn khủng hoảng tài chính toàn cầu
}

\author{
Phạm Minh Chính
}

Tạp chí Cộng sản

January 24, 2009

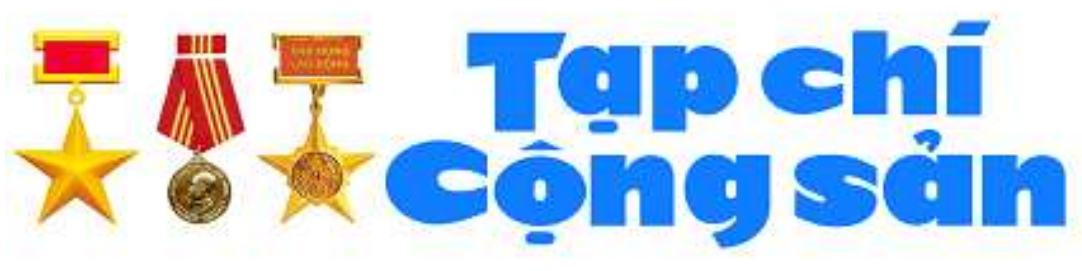

https://tapchicongsan.org.vn/en_US/web/guest/hoat-ong-cua-lanh-ao-ang-nhanuoc/-/2018/8233/bao-dam-an-ninh-kinh-te-trong-giai-doan-khung-hoang-taichinh-toan-cau.aspx 


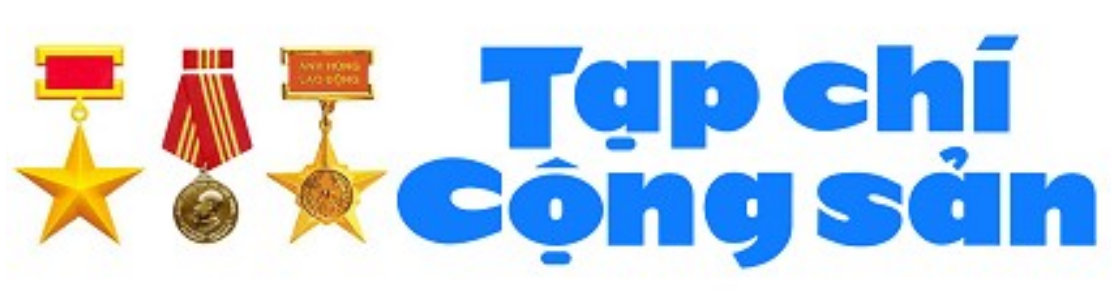

CƠ QUAN LÝ LUẬN CHÍNH TR! CỦA BAN CHẤP HÀNH

TRUNG ƯƠNG ĐẢNG CộNG SẢN VIẸTT NAM

๒าราวาอ 中文 ENGLISH ESPAÑOL

\section{CÁC CHUYÊN MỤC KHÁC}

\section{Bảo đảm an ninh kinh tế trong giai đoạn khủng hoảng tài chính toàn cầu}

PHẠ MINH CHÍNH

14:30, ngày 24-01-2009

Cơn bão tài chính toàn cầu năm 2008 đã "quét" qua nhiều quốc gia và châu lục, không những làm sụp đổ nhiều tổ chức tài chính lớn, nhỏ với hàng trăm năm tuổi, mà còn kéo theo quy mô phá sản cấp quốc gia (Iceland). Song cơn bão này chưa hề có dấu hiệu suy giảm, và không ai biết nó còn kéo dài bao lâu, không ai có thể lường hết được sức công phá của nó. Nhanh chóng thực thi một số biện pháp nhằm bảo đảm an ninh kinh tế trong giai đoạn này là việc thực sự cấp bách đối với mỗi quốc gia hiện nay.

\section{I- Bản chất của khủng hoảng tài chính toàn cầu 2008}

\section{1- Diễn biến khủng hoảng tài chính}

Mười năm sau cuộc khủng hoảng tài chính - tiền tệ châu Á, thế giới lại đứng trước một cuộc khủng hoảng tài chính mà mức độ nghiêm trọng và khả năng tàn phá lớn hơn gấp nhiều lần. Xuất phát từ khủng hoảng nợ dưới chuẩn của Mỹ, do những chính sách tín dụng dễ dãi của các ngân hàng và tổ chức đầu tư bất động sản, thông qua mối quan hệ kinh doanh chằng chịt của hệ thống ngân hàng thời đại toàn cầu hoá, cuộc khủng hoảng tài chính năm 2008 đã nhanh chóng lan rộng ra nhiều lĩnh vực và khu vực trên toàn thế giới.

Cả thế giới bàng hoàng khi hàng loạt các định chế tài chính lớn lần lượt sụp đổ, tiêu biểu nhất là sự phá sản của Lehman Brothers, ngân hàng mà chỉ một năm trước đó còn được đánh giá là ngân hàng đầu tư bất động sản tốt nhất nước Mỹ. Tiếp đó là các tên tuổi như Bradford and Bingley (Anh), Hypo Real Estate 
(Đức), Fortis (Bỉ), Dexia (Pháp), Yamamoto Life (Nhật Bản)... Tính tới cuối tháng 11 năm 2008, số ngân hàng thương mại phá sản ở Mỹ đã lên tới 22 (trong đó đứng đầu danh sách những thể chế tài chính xấu số này là Washington Mutual với tổng tài sản 307 tỉ USD), và chưa có dấu hiệu dừng lại. Số ngân hàng nằm trong danh sách "có vấn đề"(1) vẫn tăng không ngừng, đạt tới con số 171 trong quý III/2008, mức cao nhất kể từ năm 1995.

Dưới tác động của khủng hoảng tài chính, các hoạt động thương mại, đầu tư, tiêu dùng của mỗi quốc gia đều sụt giảm mạnh, nguy cơ suy thoái kinh tế đang đe dọa. Thậm chí, nhiều nước đang lâm vào tình trạng phá sản cấp quốc gia.

Những phản ứng bị động và lúng túng của nhiều quốc gia và tổ chức quốc tế cho thấy sự bất ngờ của thế giới trước cuộc khủng hoảng và tầm ảnh hưởng của nó. Sức tàn phá của "cơn sóng thần" tài chính đến từ Mỹ mạnh đến mức không một quốc gia nào có thể tự mình giải quyết cuộc khủng hoảng, mà đòi hỏi phải có sự chung tay của cộng đồng quốc tế. Khủng hoảng tài chính và cách giải quyết hậu quả đang trở thành chương trình nghị sự hàng đầu trên thế giới hiện nay.

\section{2- Bản chất của cuộc khủng hoảng}

Qua việc phân tích 3 nguyên nhân, đồng thời cũng là những đặc trưng như sau, có thể thấy được bản chất, sức tàn phá khủng khiếp của cơn bão tài chính tới an ninh kinh tế, chính trị và ổn định xã hội của các quốc gia trên thế giới.

Khủng hoảng hàng hoá (giống khủng hoảng 1973-1975). Điểm nổi bật là khủng hoảng năng lượng và lương thực, thực phẩm (đặc biệt giá gạo đã tăng trên 1.000 USD/tấn vào tháng 4/2008 và giá dầu lên 147 USD/thùng vào tháng 7/2008). Việc bùng nổ giá cả diễn ra do nguồn cung hạn chế trong khi nhu cầu tăng cao, dự trữ thấp và đặc biệt là sự gia tăng hoạt động của giới đầu cơ quốc tế. Khủng hoảng hàng hoá đã khiến tình trạng bất ổn xã hội xảy ra ở nhiều quốc gia, đe doạ nghiêm trọng tới an ninh chính trị. Hàng loạt các cuộc biểu tình, bạo động đã diễn ra ở Ai Cập, Bờ Biển Ngà, Ca-mơ-run, Hai-ti, Mô-ri-ta-ni, E-thi-ô-pia, Ma-đa-gat-xca, Phi-lip-pin, In-đô-nê-xi-a..., phản đối việc giá lương thực tăng quá nhanh. Nỗi lo về giá lương thực chưa nguôi ngoai thì việc giá năng lượng tăng kỷ lục đã khiến các cuộc biểu tình diễn ra ở khắp nơi trên thế giới, từ Anh, Pháp, Tây Ban Nha, Bồ Đào Nha cho tới các nước châu Á như Hàn Quốc, Ân Độ, In-đô-nê-xi-a, Thái Lan...

Khủng hoảng cơ cấu (giống khủng hoảng 1929-1933). Đây là hệ quả của việc đầu tư quá nhiều, quá tập trung vào lĩnh vực bất động sản và thị trường chứng khoán, trong khi lĩnh vực nghiên cứu khoa học, phát triển sản xuất không được đầu tư đúng mức. Hậu quả là thị trường chứng khoán, bất động sản và tín dụng ngân hàng "tăng trưởng nóng", giá trị "ảo" lớn gấp nhiều lần giá trị thật, dẫn đến mất cân đối cơ cấu tài chính, khủng hoảng cơ cấu kinh tế vĩ mô. Điều nguy hiểm ở chỗ, trong bối cảnh toàn cầu hoá hiện nay, 
quy mô hoạt động tài chính ngân hàng đã vượt ra khỏi biên giới quốc gia, các tập đoàn tài chính - ngân hàng hoạt động và phát triển trong sự liên kết và phụ thuộc lẫn nhau trên phạm vi toàn cầu (trước khi phá sản, ngân hàng Lehman Brothers quản lý 639 tỉ USD tài sản, 25.000 nhân viên và có chi nhánh ở hầu hết các nước trên thế giới; AIG-tập đoàn bảo hiểm lớn nhất tại Mỹ có chi nhánh hoạt động trên 130 quốc gia...). Do đó, khi một tập đoàn tài chính sụp đổ hay một ngân hàng tại một quốc gia phát triển phá sản đã ảnh hưởng trực tiếp đến an ninh tài chính của hàng loạt nước khác.

Khủng hoảng thể chế quản lý kinh tế - tài chính. Thể chế quản lý kinh tế được áp dụng từ nhiều năm nay tại các nước phát triển, đặc biệt Mỹ và $E U$, bó hẹp trong phạm vi một nền kinh tế, trong khi các hoạt động tài chính liên thông trên quy mô toàn cầu. Vai trò điều tiết của nhà nước giảm dần trong xu thế toàn cầu hoá và quốc tế hoá, chính phủ không kiểm soát được các hoạt động đầu cơ quốc tế, việc theo đuổi chính sách phát triển kinh tế thị trường với quan điểm tự do tuyệt đối, buông lỏng vai trò quản lý, điều tiết của nhà nước đối với thị trường... là những nguyên nhân cơ bản dẫn đến tình trạng khủng hoảng. Do đó, khi thị trường phát triển quá nóng, không còn tuân theo quy luật cung - cầu, đã dẫn đến sự rối loạn trong hoạt động của hệ thống tài chính - ngân hàng.

Ba đặc trưng trên có mối quan hệ hữu cơ', tác động lẫn nhau rất sâu sắc, làm cho tình hình diễn biến phức tạp và khó lường, làm giảm hiệu quả các biện pháp can thiệp cũng như đẩy nhanh và gia tăng hậu quả cuộc khủng hoảng. Trong đó, khủng hoảng thể chế, nhất là trong lĩnh vực quản lý tài chính - ngân hàng là đặc trưng nổi bật và có tính chất nghiêm trọng nhất, chi phối toàn bộ cuộc khủng hoảng tài chính đang diễn ra trên phạm vi toàn cầu. Cuộc khủng hoảng sẽ còn diễn biến phức tạp, hậu quả sẽ còn hết sức nghiêm trọng, kéo dài chưa thể lường hết, đặc biệt là những tác động tới an ninh kinh tế của các quốc gia.

\section{II- Những biện pháp nhằm bảo đảm an ninh kinh tế}

\section{1- Những vấn đề rút ra từ các biện pháp đối phó khủng hoảng của các quốc gia trên thế giới}

Trước ảnh hưởng sâu rộng của cuộc khủng hoảng tới hệ thống tài chính- ngân hàng và toàn bộ nền kinh tế, đồng loạt các quốc gia, các tổ chức quốc tế đã đề ra nhiều biện pháp khẩn cấp nhằm ngăn chặn sự lan rộng của cuộc khủng hoảng, đồng thời tiến hành một số cải cách trong quản lý, điều hành hệ thống tài chính. Qua theo dõi, bước đầu có thể rút ra một số vấn đề sau:

Tất cả các quốc gia đều đang sử dụng các công cụ can thiệp trực tiếp với mức độ khác nhau vào nền kinh tế, đặc biệt là lĩnh vực tài chính - tiền tệ. Kinh tế thị trường theo mô hình laissez-faire (để thị trường điều tiết hoàn toàn, không có can thiệp của nhà nước), theo nhận định của các nhà lãnh đạo phương Tây, giờ đây đã không còn phù hợp. Tổng thống Pháp N.Xác-cô-di cho rằng, "cuộc khủng hoảng là sự thoái hoá, lệch lạc của nền kinh tế thị trường", và, "các nước phải tìm ra được một sự cân bằng mới giữa vai trò của 
nhà nước và thị trường". Còn ở Mỹ, các hành động can thiệp trực tiếp vào nền kinh tế, cụ thể là hệ thống tài chính Phố Uôn đang trở thành điều hiển nhiên và người ta đang quen dần với điều đó sau gần một thế kỷ của chính sách tự do kinh tế. Như vậy, vấn đề không nằm ở chỗ, chính phủ có can thiệp hay không, mà điều quan trọng là can thiệp với liều lượng, phương pháp và thời điểm như thế nào. Đó cũng là nhu cầu khách quan vì thị trường luôn có khiếm khuyết, như cách nói của nhà tài chính Gióoc-giơ Sô-rốt (George Soros): "Thị trường hay phụ lòng tin của các chủ thể kinh tế chính ngay khi người ta cần nó nhất".

Chủ quyền kinh tế của các quốc gia, nhất là những nước có nền kinh tế phụ thuộc vào nước ngoài và nội lực kinh tế thấp sẽ bi ảnh hưởng khi phải chấp nhận những điều kiện ràng buộc của các tổ chức kinh tế quốc tế. Để hỗ trợ hệ thống tài chính toàn cầu, Quỹ Tiền tệ quốc tế (IMF) đã thiết lập các chương trình cho vay khẩn cấp trị giá hàng trăm tỉ USD ${ }^{(2)}$. Tuy nhiên, xét về góc độ an ninh kinh tế quốc gia, điều mà các chuyên gia lo ngại chính là những điều kiện ràng buộc phức tạp của IMF đối với khoản vay, bởi những điều kiện ấy cho phép tổ chức này có thể can thiệp sâu vào việc quá trình hoạch định chính sách vĩ mô của mỗi nước thông qua việc kiểm soát chi tiêu công. Chính vì vậy, trong cuộc khủng hoảng tài chính Đông Á năm 1997, Chính phủ Ma-lai-xi-a đã quyết định kiểm soát ngoại hối, thay vì chịu những tác động của IMF. Vào năm ngoái, chủ quyền trong lĩnh vực tài chính - ngân hàng đã từng được Thủ tướng Nga Pu-tin đưa ra để từ chối gia nhập Tổ chức Thương mại thế giới (WTO).

Quá trình tiếp cận và giải quyết khủng hoảng tài chính của từng quốc gia (đặc biệt là các nước lớn, có vai trò quan trọng trên thế giới) đều xuất phát từ việc bảo đảm an ninh kinh tế và lợi ích cục bộ của quốc gia. Điều này thể hiện rõ qua hai thể chế liên minh kinh tế chính trị chặt chẽ nhất hiện nay ở phương Tây là Liên minh châu Âu (EU) và Khối các nước công nghiệp phát triển thế giới (G7).

Khi cuộc khủng hoảng tài chính từ Mỹ lan sang châu Âu, ngay lập tức xuất hiện sự chia rẽ trong nội bộ EU về phương thức đối phó chung, thể hiện ở sự thất bại trong kế hoạch lập Quỹ đối phó khủng hoảng. Hiện tại, các nước EU có xu hướng mỗi nước tự giải quyết vấn đề trong hệ thống tài chính ngân hàng của mình theo quan điểm lợi ích của từng nước. Hơn thế nữa, người ta đã thấy sự tương trợ lẫn nhau trong thời kỳ khủng hoảng là một khái niệm khá xa vời. Bốn nước lớn đại diện lợi ích cho EU (Pháp, Đức, Anh, I-ta-li-a), trong nhiều cuộc họp chung, bàn về biện pháp giải quyết khủng hoảng cho châu Âu, hầu như đã không có phản ứng gì với những khó khăn, với nguy cơ phá sản cấp quốc gia của Ai-len, Hung-ga-ry, Hy Lạp...

Khối G7 cũng không có một chương trình, hay một chiến lược thống nhất nào để tìm lối thoát cho cuộc khủng hoảng. Thậm chí, trong cuộc họp thượng đỉnh vừa qua, Mỹ, Anh thể hiện quan điểm không muốn mở rộng sự tham gia đến Trung Quốc, Ân Độ, Bra-xin, Nam Phi và các nước có tiềm lực ở Trung Đông để giải quyết cuộc khủng hoảng, bởi lo ngại vai trò sẽ bị giảm sút trong nền kinh tế tài chính toàn cầu. 
Đáp lại quan điểm cục bộ của các nước phương Tây, những liên minh tiền tệ song phương và khu vực đang hình thành để hạn chế sử dụng đồng USD trong thanh toán quốc tế, cụ thể như 5 nước vùng Vịnh (Ba-ranh, Kô-oét, Qua-ta, A-rập Xê-út và Các tiểu vương quốc Ả rập thống nhất) thành lập liên minh tiền tệ đưa đồng "Đin-na vùng Vịnh" vào sử dụng làm đồng tiền chung; Bra-xin và Ác-hen-ti-na, Nga và Trung Quốc chấp nhận sử dụng đồng nội tệ trong trao đổi thương mại song phương...

\section{2- Những biện pháp cụ thể nhằm bảo đảm an ninh kinh tế cho Việt Nam trong giai đoạn hiện nay}

\section{a. Bối cảnh}

Cho đến thời điểm này, dưới sự lãnh đạo, điều hành quyết liệt của Đảng và Chính phủ, sự cố gắng của các cấp, ngành, các tầng lớp nhân dân và doanh nghiệp, nền kinh tế vẫn duy trì được tốc độ tăng trưởng và phát triển khá ổn định; lạm phát được kiềm chế; đầu tư trực tiếp của nước ngoài tiếp tục tăng (11 tháng đầu năm 2008 tăng 44,2\% so với cùng kỳ năm 2007), chỉ số giá tiêu dùng tháng tháng 10 và 11 đã ngừng tăng, lãi suất tín dụng giảm nhanh tạo điều kiện thuận lợi cho các doanh nghiệp tiếp cận các nguồn vốn vay; chính sách an sinh xã hội được bảo đảm, riêng trợ cấp xã hội trong 11 tháng qua là gần 20 nghìn tỉ đồng (năm 2007 gần 5 nghìn tỉ đồng), ước tăng trưởng GDP năm 2008 đạt mức 6,7\%.

Tuy nhiên, do đang trong quá trình hội nhập ngày càng sâu rộng, khủng hoảng tài chính và suy thoái kinh tế toàn cầu đã có những tác động nhất định tới nền kinh tế của nước ta cho dù Chính phủ đã rất nỗ lực chèo chống con thuyền kinh tế trong bối cảnh lạm phát cao hồi đầu năm.

Giá trị sản xuất công nghiệp chỉ tăng 15\% so với cùng kỳ năm 2007 (tháng 11/2007 so với cùng kỳ năm trước tăng 17,4\%), tháng 11 là tháng thứ 5 liên tiếp (kể từ tháng 7) tốc độ tăng giá trị sản xuất công nghiệp bị giảm sút. Giá trị gia tăng ngành xây dựng 9 tháng đầu năm 2009 giảm 0,33\% so với cùng kỳ năm trước.

Kim ngạch xuất khẩu, đầu tư, thu ngân sách, thị trường chứng khoán, du lịch, vận tải, dịch vụ và sức mua đều giảm sút so với những tháng gần đây.

Trên thị trường tài chính, lãi suất cơ bản đã liên tục được điều chỉnh giảm kéo theo lãi suất tín dụng giảm nhanh nhưng nhiều doanh nghiệp vẫn chưa tiếp cận được nguồn vốn.

Dấu hiệu thiểu phát đã bắt đầu xuất hiện với chỉ số giá tiêu dùng liên tục giảm trong 2 tháng 10 và 11 .

Hội nhập là tất yếu, là xu thế khách quan không thể đảo ngược. Nhưng hội nhập trong điều kiện nước ta có các đặc thù như, đi lên từ một nước nghèo, trải qua chiến tranh tàn khốc, quán tính của cơ chế bao cấp đang còn nặng nề và sâu rộng, kể cả trong nhận thức tư duy và hành động. Chúng ta tiến hành đổi mới, công nghiệp hoá đất nước trong điều kiện thiếu nguồn nhân lực có trình độ quốc tế, nhập khẩu chủ 
yếu các nguyên liệu đầu vào, trong khi đó các thế lực thù địch luôn nhòm ngó, tìm kiếm những sơ hở, lợi dụng tình hình khó khăn để công kích gây chia rẽ nội bộ, làm giảm uy tín của Đảng, tác động xấu đến tâm lý nhân dân, làm ảnh hưởng quản lý xã hội, dẫn đến mất ổn định chính trị.

b. Các vấn đề cần giải quyết

Để đảm bảo an ninh kinh tế trong thời kỳ hội nhập, nhất là trong bối cảnh khủng hoảng tài chính hiện nay, cần đặc biệt quan tâm quán triệt và tổ chức thực hiện tốt các vấn đề sau:

- Không ngừng củng cố an ninh quốc phòng, giữ vững ổn định chính trị, xã hội trong mọi tình huống nhằm phục vụ phát triển kinh tế. Đảng ta đã xác định, phát triển kinh tế là nhiệm vụ trung tâm, và trong bốn nguy cơ đối với nước ta, tụt hậu về kinh tế là nguy cơ hàng đầu. Trong thời điểm khủng hoảng toàn cầu hiện nay, luận điểm này càng có giá trị. Phát triển kinh tế sẽ tạo điều kiện để giữ vững ổn định chính trị, xã hội, và ngược lại, ổn định về chính trị đang là yếu tố "ghi điểm" nhất trong môi trường đầu tư kinh doanh của Việt Nam trên bản đồ kinh doanh toàn cầu hiện nay.

- Giữ vững quan điểm nhất quán về hội nhập trên cơ sở phải giữ độc lập tự chủ trong điều hành kinh tế vĩ mô, trong đó cốt lõi là đảm bảo an ninh tài chính, an ninh năng lượng, an ninh lương thực, an ninh thông tin... mang bản sắc Việt Nam. Khi xảy ra biến động hoặc khủng hoảng kinh tế, các định chế tài chính thế giới và khu vực (Quỹ Tiền tệ quốc tế, Ngân hàng Thế giới, Ngân hàng Phát triển châu Á...) thường đưa ra những lời khuyên khác nhau theo từng thời điểm. Việc lắng nghe là cần thiết nhưng xử lý cụ thể trong từng hoàn cảnh sao cho phù hợp thì không ai hiểu mình bằng chính bản thân mình.

- Kiểm soát chặt chẽ các phương tiện truyền thông, đặc biệt là trong việc tuyên truyền sử dụng các công cụ tiền tệ và tài khoá. Tất cả các khía cạnh của an ninh kinh tế trong quá trình hội nhập, đặc biệt trong bối cảnh khủng hoảng có mối quan hệ chặt chẽ với an ninh thông tin. Thông tin, truyền thông có vai trò và tác động tâm lý rất lớn đối với đông đảo công chúng và bộ máy quản lý kinh tế. Thông qua truyền thông, cơ quan quản lý, điều hành có điều kiện tuyên truyền, giải thích rõ các vấn đề đang diễn ra, lộ trình giải quyết và huy động nguồn lực xã hội hợp lý. Truyền thông cũng góp phần tạo ra sự đồng thuận giữa các tác nhân kinh tế, tinh thần đoàn kết vượt qua khó khăn, giữ vững ổn định xã hội và an ninh kinh tế. Truyền thông tốt, có tính định hướng chính xác luôn có tác dụng tích cực, mang lại hiệu quả bình ổn, hạn chế đầu cơ, đặc biệt quan trọng với các thị trường có tính dao động mạnh theo tâm lý cá nhân như thị trường chứng khoán, năng lượng và lương thực thực phẩm.

- Không để tâm lý chủ quan, mất cảnh giác tồn tại trong các ngành, các cấp. Thay vào đó, cần tăng cường sự phối hợp điều hành, dự báo, nghiên cứu ở tầm vĩ mô của các bộ, ngành chức năng. Điều này đóng một vai trò vô cùng quan trọng trong bảo đảm ổn định kinh tế, an ninh tài chính tiền tệ. Bởi cho đến nay, chưa ai đánh giá được chính xác mức độ diễn biến tiếp theo của cuộc khủng hoảng này, trong khi tác 
động của nó tới nền kinh tế Việt Nam sẽ có độ trễ nhất định. Cuộc khủng hoảng Đông Á năm 1997 với mức độ không lớn như cuộc khủng hoảng lần này cũng đã làm tốc độ tăng trưởng GDP của nước ta giảm từ 8,2\% (năm 1997) xuống dưới $6 \%$ hai năm sau đó (1999). Điều này càng trở nên phức tạp hơn khi hiện nay nước ta đã hội nhập sâu hơn vào kinh tế khu vực và thế giới so với thời điểm năm 1997. Đoàn kết và thống nhất trong tư tưởng, nhận thức để đưa ra các giải pháp, đối sách phù hợp là điều kiện tiên quyết trong xử lý các diễn biến kinh tế phức tạp không chỉ đang diễn ra mà có thể còn lặp lại ở mức độ nghiêm trọng hơn, ảnh hưởng lâu dài hơn đối với ổn định xã hội và an ninh kinh tế quốc gia.

- Chú trọng nguyên tắc điều hành nền kinh tế thị trường có sự điều tiết của Nhà nước. Cần nhận thức đầy đủ về nền kinh tế thị trường, xây dựng cơ chế phản ứng và điều hành với mức độ can thiệp, kiểm soát thích hợp. Nền kinh tế nước ta từng chịu ảnh hưởng lan truyền của khủng hoảng tài chính tiền tệ châu Á 1997-1998, tuy nhiên, tình hình kinh tế hiện nay rất khác biệt và phức tạp hơn nhiều do có sự xuất hiện của thị trường chứng khoán, các công cụ tài chính mới, lực lượng tài chính quốc tế, trong mối liên thông các thị trường bất động sản - tiền tệ và vốn, đòi hỏi các cơ quan nghiên cứu, điều hành phải nhận thức đầy đủ bản chất của sự khác biệt này cũng như quá trình chuyển đổi của nền kinh tế để xác định quy mô, mức độ can thiệp cần thiết khi xảy ra biến động kinh tế./.

(1) Ngân hàng có vấn đề: là định chế tài chính đang trên bờ vực phá sản hoặc đang phải đương đầu với khó khăn nghiêm trọng về tài chính và quản lý (theo định nghĩa của Tập đoàn Bảo hiểm Tiền gửi Liên Bang Mỹ (FDIC).

(2) Quỹ Tiền tệ quốc tế đã cho Ai-len vay 2 tỉ USD, Hung-ga-ry vay 15,7 tỉ USD, U-crai-na vay 16,5 tỉ USD và hiện có khoảng 12 nước đang thương thảo để nhận được sự hỗ trợ tài chính.

\section{BÀI CÙNG CHỦ ĐÊ}

Xuân Kỷ Sửu 1949, Bác Hồ trả lời báo chí (24/01/2009)

Hỗ trợ người nghèo đón Tết (24/01/2009)

Chung tay lo Tết cho người nghèo, gia đình chính sách (24/01/2009)

Bảo đảm an ninh kinh tế trong giai đoạn khủng hoảng tài chính toàn cầu (24/01/2009)

Đông Bắc Á năm 2008: Những sự kiện an ninh đối ngoại nổi bật (24/01/2009)

Nhưng năm Sửu đáng nhớ trong thế kỷ XX (24/01/2009) 


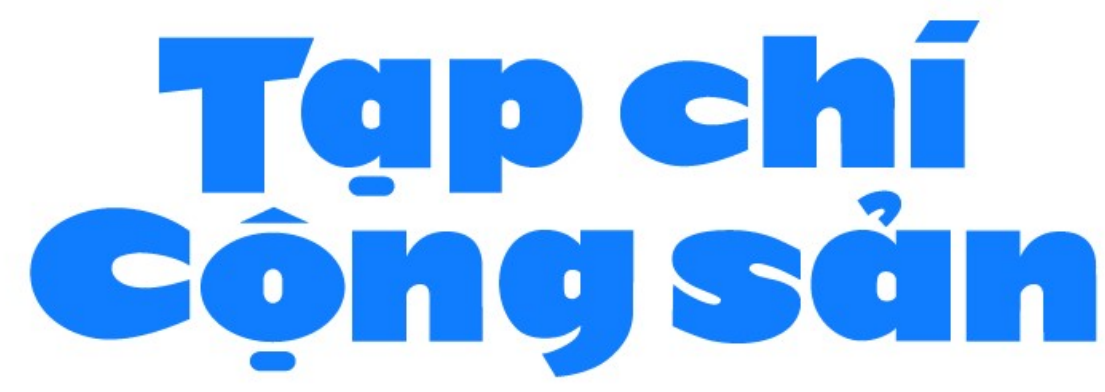

NHỮNG CHẶNG ĐƯỜNG PHÁT TRIỂN

TỔNG BIÊN TẬP: PGS,TS. ĐOÀN MINH HUẤN

\section{Bộ Biên tập:}

Địa chỉ: Số 28, Trần Bình Trọng - thành phố Hà Nội

Điện thoại: 02439429753 - Fax: 02439429754 
Email: tapchicongsandientu@tccs.org.vn

\section{Cơ quan Thường trực tại miền Trung - Tây Nguyên:}

Số 26 Trần Phú, thành phố Đà Nẵng

Điện thoại: (080) 51 301; Fax: (080) 51303

\section{Cơ quan Thường trực tại miền Nam:}

Địa chỉ: Số 19 Phạm Ngọc Thạch,

Thành phố Hồ Chí Minh

Điện thoại: (080) 84083; Fax: (080) 84081

\section{Văn phòng đại diện tại thành phố Cần Thơ:}

Địa chỉ: Số 86 Nguyễn Trãi, thành phố Cần Thơ

Điện thoại/Fax: (0710)6250868

\section{- HÀNH CHÍNH ĐIÊN TỬ 4}

LIÊN HẸ GỬI BÀI VÀ ĐÓNG GÓPÝ KIẾN

LIÊN HẸ QUẢNG CÁO: 08046138

@Bản quyền thuộc về Tạp chí Cộng sản

Giấy phép số 436/GP-BTTTT ngày 14-10-2019 của Bộ Thông tin và Truyền thông. Mọi hành động sử dụng nội dung đăng tải trên Tạp chí Cộng sản điện tử tại địa chỉ www.tapchicongsan.org.vn phải dẫn nguồn và có sự đồng ý bằng văn bản của Tạp chí Cộng sản 